\title{
EFFECT OF NOISE POLLUTION ON HEARING THRESHOLD IN SCHOOL CHILDREN OF BANGALORE CITY
}

Hareesha Acharya, M. S. Kusumadevi, Shivakumar Veeraiah

1. Senior Medical Officer. Department of Physiology, Bangalore Medical College \& Research Institute.

2. Associate Professor. Department of Physiology, Bangalore Medical College \& Research Institute.

3. Professor \& Head. Department of Physiology, Bangalore Medical College \& Research Institute.

\section{CORRESPONDING AUTHOR:}

Dr. M. S. Kusumadevi,

$1962,4^{\text {th }}$ cross, $18^{\text {th }}$ A main Road,

J. P. Nagar $2^{\text {nd }}$ phase,

Bangalore -560078 .

E-mail: kusumadevi36@gmail.com

ABSTRACT: BACKGROUND: Noise pollution in urban cities is a serious problem and steadily increasing over the years. Literature states that the noise pollution has negative effect on the child's intellectual ability. So the present study was undertaken to find the effect of noise pollution on the auditory thresholds of school children using pure tone audiometer so that appropriate preventive measures can be undertaken in the initial stages. OBJECTIVES:

1. To make pure tone audiometric assessment of auditory acuity in school children situated in a noise polluted area.

2. To make pure tone audiometric assessment of auditory acuity in school children situated in a less noisy area.

3. To compare these two groups to find out the effect of noise pollution on auditory thresholds.

MATERIALS AND METHODS: Two hundred middle school children were selected from two different areas of Bangalore city having different noise levels. Group A consisted of one hundred students selected from less noisy area. Group B consisted of one hundred students from more noisy area. Hearing assessment was made using pure tone audiometry measuring the thresholds of both air conduction and bone conduction. Data was analysed for statistical significance. RESULTS AND CONCLUSION: The following conclusions were drawn after statistical analysis.

1) Children from more noisy area (group $B$ ) had raised air conduction thresholds at all frequencies i.e. $0.25,0.5,1,2,4,6$ and $8 \mathrm{kHz}$..

2) Children from more noisy area (group B) had raised bone conduction thresholds. Significant rise noted in 1, 2, and $4 \mathrm{kHz}$.

3) There exists a positive association between exposure to noisy area and rise in auditory threshold among school children.

Hence it could be suggested that regular and effective conduction of school health programmes must be done especially in urban areas which should include periodic assessment of auditory thresholds of children and appropriate measures should be initiated at early stage. Also priority should be given to noise control measures while constructing school buildings.

KEY WORDS: Noise pollution, hearing threshold, middle school children 
INTRODUCTION: The ability to communicate is a crucial aspect of human life as auditory sense is very important for communication of any kind .It is indispensable for the normal mental development of a child .Hearing impairment in children acquires a special significance as a large percentage of population affected are children. As reported from various earlier studies the prevalence rate of hearing impairment in children varies from as low as $2.7 \%$ in some studies to as high as $15 \%$ in some studies.

5 million of the world population has profound degree of hearing impairment. 120 million worldwide have hearing loss of atleast $40 \mathrm{~dB}$. 200 million have varying degree of hearing loss.(1) In India, 2 deaf babies are born per hour i.e 1/2000 to 1/6000 live births. 18000 deaf babies are added to our population every year.(1)

Children with hearing impairment often experience delayed development of speech and cognitive skills which may result in slow learning and difficulty in progressing in school. The impact of hearing impairment on child's speech, language, education and social integration depends on the level and type of hearing impairment and the age of onset especially if it begins before the age when speech normally develops.(2)

Intervention to reduce the occurrence of communication disabilities with hearing impairments are most successful if affected children are diagnosed early.(3)

Unfortunately school aged children are rarely screened for hearing loss during routine clinical examination and most school health authorities make no provision for audiometric assessment. This is usually attributable to low awareness among parents, school authorities and health care providers on the consequences of slight/mild hearing loss . The overwhelming burden of prevailing communicable and fatal diseases on the available /limited resources in most communities further divert attention away from routine auditory screening.(4)

The fact that deafness impedes the mental development of children has not been well appreciated in the developed countries by those responsible for their education. It needs the involvement of primary health workers in the same way as in the existing National Health programmes, with referral facilities to more specialized centers for further treatment.

Recently noise pollution has been of increasing concern worldwide, particularly in most urban centers. The noise problem of the modern industrial societies seem incomparable to the past given the larger sources of noise now present outdoors and indoors. According to the World Health Organization traffic noise is one of the main sources of environmental noise exposure in urban communities.

Like the home and the work place, school is also an important microenvironment. The school is important for the cognitive, creative, and social development of children. Schools are therefore expected to ensure the best possible conditions for a child's physical and intellectual development, including control of excess environmental noise. According to W.H.O the permissible noise level in school environments should not exceed $35 \mathrm{~dB}$. Exposure for more than six hours a day to sound in excess of $85 \mathrm{~dB}$ is potentially hazardous to health.

In less developed countries like India, many children do not have access to ideal or serene learning environments. Noise control in the school environment is a real public health challenge. (5)

As there is lack of data regarding hearing ability in school going children, this study is an attempt to evaluate hearing ability in these children in Bangalore city.

The hypothesis tested is that the noise pollution significantly increases the hearing thresholds among school going children. 
AIMS AND OBJECTIVES: The purpose of the present study is to evaluate the effect of noise pollution on auditory thresholds in middle school children of Bangalore city using pure tone audiometer.

CLASSIFICATION OF HEARING IMPAIRMENT IN CHILDREN as per ministry of social justice and empowerment Government of India, New Delhi-

Category
I
II a)
II b)
III

\section{type of impairment}

mild hearing impairment moderate hearing impairment severe hearing impairment a)profound hearing impairment

b) total deafness

\section{dB Level (Hearing loss)}

26-40 dB in better ear

41-60 dB in better ear

61-70 dB in better ear

71-90 dB

$91 \mathrm{~dB}$ and above in better

MATERIALS AND METHODS SOURCE OF DATA: School going children of 10-13 years of age group were selected from schools across Bengaluru south city. Two schools were selected from two different areas of Bangalore city each of them from different noise levels. Group A consisted of students from govt. middle school Vijayanagar where the day time noise level was $63.3 \mathrm{~dB}$ and group B consisted of students from govt school fort where the day time noise level measured was $79.0 \mathrm{~dB}$.

SELECTION OF SUBJECTS: The study group consisting of 200 school children of both genders of Bengaluru city located in the same school at least for 5 years. The selected schools were located in populated areas having the same social, emotional and nitritional levels.

\section{Inclusion criteria;}

1. School going children of both genders of Bengaluru city.

2. Age 10-13 years.

3. Located in the same school at least since 5 years.

\section{Exclusion criteria;}

1. Children whose parents are not willing to enroll their children in the study.

2. Children with complaints of diminished hearing with complications.

3. Children with profound or total hearing loss, where the degree of hearing loss is so severe that the child is not benefited with hearing aid also.

4. Children with hearing loss of more than $90 \mathrm{~dB}$ detected on audiometry.

Written consent was obtained from the subjects parents after explaining the procedure. A general physical and systemic examination was conducted in all subjects. Also a detailed ear, nose, and throat examination was carried out to rule out sub- clinical infection or other pathology. An assessment of auditory acuity using a pure tone audiometer (ARPHI 500 MK1) was done.

Auditory acuity is the lowest level of sound threshold in decibels, at a particular frequency, at which the human ear can perceive it as a sound. The parameter of auditory acuity studied was the hearing threshold for air conduction and bone conduction at different frequencies. Pure tone audiometer contains sound thresholds in decibels and sound frequencies in Hertz. Using this audiometer, audiograms were recorded separately for both ears of the 
selected subjects in a sound proof room. The audiogram chart thus obtained depicted the auditory acuity of the particular ear.

Hearing thresholds for air conduction and bone conduction at different frequencies (as in the pure tone audiometer) of the subjects was recorded using pure tone audiometer (ARPHI 500 MK1) according to American Society for Speech and Hearing Association [ASHA] 2005 Guidelines for manual pure-tone threshold audiometry (PTA). The recordings were entered in their respective proforma, based on which master chart was developed

RESULTS AND ANALYSIS: The present study is a comparative study comparing the hearing thresholds of school going children of less noisy area with those of more noisy area of Bangalore city .

Group A: 100 children of age group between 10-13 years from less noisy area.

Group B: 100 children of age group between 10-13 years from more noisy area.

The parameters studied are the hearing thresholds in decibels of both the groups.

The data was subjected to appropriate statistical treatment. The following are the statistical methods applied in this study.

Statistical Methods: (22-25) Descriptive statistical analysis has been carried out in the present study. Results on continuous measurements are presented on Mean \pm SD (Min-Max) and results on categorical measurements are presented in Number (\%). Significance is assessed at 5 $\%$ level of significance. Student $t$ test ( two tailed, independent) has been used to find the significance of study parameters on continuous scale between two groups Inter group analysis) on metric parameters, Chi-square/ Fisher Exact test has been used to find the significance of study parameters on categorical scale between two or more groups.

Statistical software: The Statistical software namely SAS 9.2, SPSS 15.0, Stata 10.1, MedCalc 9.0.1 Systat 12.0 and $R$ environment ver.2.11.1 were used for the analysis of the data and Microsoft word and Excel have been used to generate graphs, tables etc.

Table 2: Comparison of age distribution of children studied

\begin{tabular}{|l|l|l|l|l|}
\hline \multirow{2}{*}{ Age in years } & \multicolumn{2}{|l|}{ Group A } & \multicolumn{2}{l|}{ Group B } \\
\cline { 2 - 5 } & No & $\%$ & No & $\%$ \\
\hline 10 & 27 & 27.0 & 28 & 28.0 \\
\hline 11 & 27 & 27.0 & 22 & 22.0 \\
\hline 12 & 22 & 22.0 & 29 & 29.0 \\
\hline 13 & 24 & 24.0 & 21 & 21.0 \\
\hline Total & 100 & 100.0 & 100 & 100.0 \\
\hline Mean \pm SD & $11.43 \pm 1.13$ & $11.43 \pm 1.11$ \\
\hline
\end{tabular}

The age distribution of subjects included in the study is depicted in table 2 and graph 1 . The study groups are age matched as the $\mathrm{p}$ value is 1.000 . 
Table 3: Gender distribution of children studied

\begin{tabular}{|l|l|l|l|l|}
\hline \multirow{2}{*}{ Gender } & \multicolumn{2}{|l|}{ Group A } & \multicolumn{2}{l|}{ Group B } \\
\cline { 2 - 5 } & No & $\mathbf{\%}$ & No & \% \\
\hline Male & 55 & 55.0 & 47 & 47.0 \\
\hline Female & 45 & 45.0 & 53 & 53.0 \\
\hline Total & 100 & 100.0 & 100 & 100.0 \\
\hline
\end{tabular}

Samples are gender matched with $\mathrm{p}=0.258$

Table 4: Comparison of ear threshold (auditory assessment) in two groups of children in right ear

\begin{tabular}{|l|l|l|l|l|}
\hline Frequencies (kHz) & AC/BC & Group A & Group B & P value \\
\hline \multirow{2}{*}{$0.25(\mathrm{kHz})$} & AC & $15.60 \pm 5.01$ & $20.70 \pm 5.45$ & $<0.001^{* *}$ \\
\cline { 2 - 5 } & BC & $9.70 \pm 4.31$ & $14.75 \pm 4.73$ & $<0.001^{* *}$ \\
\hline \multirow{2}{*}{$0.5(\mathrm{kHz})$} & AC & $15.85 \pm 4.02$ & $21.20 \pm 4.61$ & $<0.001^{* *}$ \\
\cline { 2 - 5 } & BC & $9.70 \pm 3.61$ & $14.75 \pm 3.92$ & $<0.001^{* *}$ \\
\hline \multirow{2}{*}{$1.0(\mathrm{kHz})$} & AC & $17.50 \pm 5.14$ & $22.70 \pm 4.84$ & $<0.001^{* *}$ \\
\hline \multirow{2}{*}{$2(\mathrm{kHz})$} & BC & $11.30 \pm 4.53$ & $16.35 \pm 5.02$ & $<0.001^{* *}$ \\
\hline \multirow{2}{*}{$4(\mathrm{kHz})$} & AC & $18.15 \pm 3.80$ & $23.25 \pm 3.92$ & $<0.001^{* *}$ \\
\cline { 2 - 5 } & BC & $11.95 \pm 3.82$ & $17.00 \pm 4.44$ & $<0.001^{* *}$ \\
\hline $6(\mathrm{kHz})$ & AC & $23.35 \pm 3.69$ & $28.40 \pm 3.62$ & $<0.001^{* *}$ \\
\cline { 2 - 5 } & BC & $14.10 \pm 3.98$ & $19.15 \pm 3.96$ & $<0.001^{* *}$ \\
\hline $8(\mathrm{kHz})$ & AC & $14.60 \pm 4.47$ & $19.65 \pm 5.28$ & $<0.001^{* *}$ \\
\hline
\end{tabular}

From table 4 and graphs $3 \mathrm{a}$ and $3 \mathrm{~b}$, it can be inferred that the thresholds of both air conduction and bone conduction in right ear increased significantly in group B when compared with group $\mathrm{A}(\mathrm{P}<0.001)$ at all frequencies.

Table 5: Comparison of ear threshold (auditory assessment) in two groups of children in left ear

\begin{tabular}{|l|l|l|l|l|}
\hline Frequencies (kHz) & AC/BC & Group A & Group B & P value \\
\hline \multirow{2}{*}{$0.25(\mathrm{kHz})$} & AC & $15.20 \pm 4.19$ & $20.35 \pm 4.67$ & $<0.001^{* *}$ \\
\cline { 2 - 5 } & BC & $9.50 \pm 3.86$ & $14.65 \pm 4.83$ & $<0.001^{* *}$ \\
\hline
\end{tabular}


ORIGINAL ARTICLE

\begin{tabular}{|l|l|l|l|l|}
\hline \multirow{2}{*}{$0.5(\mathrm{kHz})$} & AC & $14.15 \pm 4.15$ & $19.70 \pm 5.07$ & $<0.001^{* *}$ \\
\cline { 2 - 5 } & BC & $8.35 \pm 3.89$ & $13.50 \pm 4.29$ & $<0.001^{* *}$ \\
\hline \multirow{2}{*}{$2(\mathrm{kHz})$} & AC & $17.85 \pm 4.16$ & $23.10 \pm 4.01$ & $<0.001^{* *}$ \\
\cline { 2 - 5 } & BC & $11.25 \pm 3.92$ & $16.40 \pm 4.15$ & $<0.001^{* *}$ \\
\hline \multirow{2}{*}{$4(\mathrm{kHz})$} & AC & $16.60 \pm 3.94$ & $22.10 \pm 4.39$ & $<0.001^{* *}$ \\
\cline { 2 - 5 } & BC & $10.15 \pm 4.23$ & $15.30 \pm 4.31$ & $<0.001^{* *}$ \\
\hline $6(\mathrm{kHz})$ & AC & $22.90 \pm 3.57$ & $28.05 \pm 4.43$ & $<0.001^{* *}$ \\
\hline BC & BC & $13.45 \pm 3.87$ & $18.60 \pm 4.21$ & $<0.001^{* *}$ \\
\hline $8(\mathrm{kHz})$ & AC & $14.00 \pm 4.38$ & $19.15 \pm 4.87$ & $<0.001^{* *}$ \\
\hline
\end{tabular}

From table 5 and graphs $4 \mathrm{a}$ and $4 \mathrm{~b}$, it can be noted that the thresholds of both air conduction and bone conduction in left ear increased significantly in group B when compared with group A. $(\mathrm{P}<0.001)$ at all frequencies.

Table 6: Comparison of PTA score between two groups

\begin{tabular}{|l|l|l|l|}
\hline EAR & Group A & Group B & P value \\
\hline Right & $17.17 \pm 3.32$ & $22.38 \pm 3.42$ & $<0.001^{* *}$ \\
\hline Left & $16.20 \pm 3.14$ & $21.63 \pm 3.67$ & $<0.001^{* *}$ \\
\hline
\end{tabular}

Above table and graph indicate that the pure tone average of left and right ears increased significantly in group B when compared with group A . $(\mathrm{p}<0.001)$

Table 7: Comparison of Hearing loss between two groups in Right ear.

\begin{tabular}{|l|l|l|l|l|}
\hline \multirow{2}{*}{ Hearing loss } & \multicolumn{2}{|l|}{ Group A } & Group B \\
\cline { 2 - 5 } & No & $\%$ & No & $\%$ \\
\hline Normal & 98 & 98.0 & 92 & 92.0 \\
\hline Mild & 2 & 2.0 & 8 & 8.0 \\
\hline Moderate & 0 & 0.0 & 0 & 0.0 \\
\hline Total & 100 & 100.0 & 100 & 100.0 \\
\hline Inference & \multicolumn{4}{l}{$\begin{array}{l}\text { Incidence of hearing loss is positively associated } \\
\text { with Group B with P=0.101 }\end{array}$} \\
\hline
\end{tabular}


Table 8:Comparison of Hearing loss between two groups in left ear.

\begin{tabular}{|l|l|l|l|l|}
\hline \multirow{2}{*}{ Hearing loss } & \multicolumn{2}{|l|}{ Group A } & \multicolumn{2}{l|}{ Group B } \\
\cline { 2 - 5 } & No & \% & No & \% \\
\hline Normal & 98 & 98.0 & 94 & 94.0 \\
\hline Mild & 2 & 2.0 & 4 & 4.0 \\
\hline Moderate & 0 & 0.0 & 1 & 1.0 \\
\hline Total & 100 & 100.0 & 100 & 100.0 \\
\hline Inference & \multicolumn{4}{|l|}{$\begin{array}{l}\text { Incidence of hearing loss is positively associated } \\
\text { with Group B with P=0.279 }\end{array}$} \\
\hline
\end{tabular}

The above table and graph show the degree of hearing impairment in left ear in two groups. The incidence of hearing loss is positively associated in group B.

DISCUSSION: The impact of noise on children's health and development in schools is of major public health concern. This could be greatly reduced if noise problems were taken into consideration as early as possible when a school is being designed. One of the schools selected in the present study was situated close to main roads, which potentially exposed students to excess and high level of noise from vehicular traffic, from intermittent use of vehicular horns, from the tires during the sudden use of brakes and so forth, relative to their individual proximities to the road both inside and outside of buildings (classrooms). It was noted that noise control devices like absorbers (materials have noise reduction coefficients as well) reflectors, and attenuators were absent in schools studied.

Large scale long-term studies have not been done in all at-risk populations. However, the following information may be relevant in considering noise induced hearing loss.

1. Study data suggest that children may be more vulnerable to noise-induced hearing loss than adults.

2. At high instantaneous sound pressure levels, mechanical damage to the ear may occur.

3. Risk for noise-induced hearing impairment may increase when the noise exposure is combined with exposure to vibration or with exposure to ototoxic drugs or chemicals (6).

This study was an attempt to study the effect of noise pollution on hearing thresholds of school going children. To study the effect, all confounding factors must be eliminated if specific conclusion has to be drawn. In this study, the subjects were age and gender matched in both the groups.

According to WHO the permissible noise level in school environment should not exceed $35 \mathrm{Db}(5)$. In the present study the schools were selected from those areas which had noise levels about $63.3 \mathrm{~dB}$ (group A) and $79 \mathrm{~dB}$ (group B) which were well and above the standards given by WHO.

The hearing thresholds of both the groups were compared. The analysis of the data revealed that there was statistically significant difference in air conduction thresholds between two groups at all frequencies. The group B having higher thresholds at all frequencies when compared to group A indicating that noise pollution raises the hearing thresholds. Similarly there was statistically highly significant difference in bone conduction thresholds between the two groups at all frequencies indicating that the group B has higher hearing thresholds when compared to group A. On comparing the PTA of right ear between two groups it was found that 
$2 \%$ of children in group A had mild hearing loss whereas $8 \%$ of children in group B had mild hearing loss, whereas in left ear we found $2 \%$ of group A had mild hearing loss whereas $4 \%$ of group B had mild hearing loss. The incidence of hearing loss is also positively associated with noise levels in group $B$.

A cross sectional study conducted in selected secondary schools in Ibadan, Nigeria showed that school day noise levels ranged 68.3 to $84.7 \mathrm{Db}$.0ver $60 \%$ respondents reported that vehicular traffic was major source of noise, and over $70 \%$ complained being disturbed by noise. They reported tiredness and lack of concentration as the most prevalent noise related health problems. It was concluded that the secondary school occupants in Ibadan were potentially affected by exposure to noise from mobile line sources. (5) In our study, schools were selected from those areas which had noise levels about $63.3 \mathrm{~dB}$ (group A) and $79 \mathrm{~dB}$ (group B) and the results of our study correlated with above quoted study results.

Assessment of audiometric threshold in teenaged farm children in central Wisconsin showed an increased prevalence of hearing loss among students actively involved in farm work. It was also suggested that the use of hearing protection might reduce the risk of hearing loss among the farm students. (6) In our study the incidence of hearing loss is positively associated with noise levels in group B.

A study conducted on 214 teenagers from a high school in Mexico city revealed hearing loss was found in $21 \%$ of students and the high frequency of hearing loss was found to be related to noise exposure mainly during recreational activities. (7) In our study PTA of right ear revealed that $2 \%$ of children in group $A$ had mild hearing loss whereas $8 \%$ of children in group $B$ had mild hearing loss, whereas in left ear $2 \%$ of group A had mild hearing loss whereas $4 \%$ of group B had mild hearing loss.

The third national health and nutrition examination survey conducted in United States showed that noise induced hearing threshold shifts, as measured by pure tone audiometry, was seen in $12 \%$ of children of 6 to 19 years age group. It was concluded that the children were being exposed to excessive amounts of noise and children's hearing was vulnerable to those exposure. (8) Results of our study also revealed statistically significant higher threshold in both air and bone conduction at all frequencies in group B compared to group A.

According to Hodder Arnold, exposure to excessive sound dulls hearing and may damage the ear by following mechanism. When sound is moderate, it produces temporary threshold shift which recovers if the ear is allowed to rest, the mechanism being metabolic exhaustion and recovery. When the sound is sufficiently intense, it produces a much more severe temporary threshold shift which may go on to become a permanent threshold shift. There is a critical point at which moderate TTS changes to long term PTS, which correlates with anatomical damage to the outer hair cells. The threshold for TTS is somewhere between 78 and $85 \mathrm{Db}$ and the point at which it changes from midterm to long term PTS is about $140 \mathrm{db}$. If mechanical disturbance produced by sound is sufficient to fracture the rootlet or to disturb the linkages, it will result in floppy cilium (9).

The impact of noise on children's health and development in schools imposes a potentially considerable financial burden, which could be greatly reduced if noise concerns were taken into consideration as early as possible when a school is being planned as well as during operations and maintenance of the buildings and facilities.

The school health programmes in the state should include periodic auditory assessment to detect hearing impairment among school children in the early stage so that effective preventive measures can be undertaken to ensure the best possible environment for child's intellectual 
development. Other measures include health education, training, exposure assessment, hearing protection and noise control whenever feasible should be implemented. The noise control measures should include preferring relatively noise free areas for constructing schools within city limits, constructing school buildings with sound absorbers and prohibiting sound horns in the vicinity of schools. The goal is to promote enhanced learning environments for children free from excess environmental noise, which will also assist the productivity and improve the health of adult staff.

Based on the results of the study conducted by Ramazan Mirzaei et al, they suggested that due to the increasing trends of city population and traffic loads on streets, there is a need for traffic management, increased knowledge, community participation and comprehensive planning in order to improve the current state of noise pollution.(10)

LIMITATIONS OF THIS STUDY: The present study is a case-control study where the sample size is very small. A large population based study is required to conclude the results.

Pure tone audiometry is a subjective test. There are chances of errors while recording auditory thresholds. The results need to be confirmed by objective tests such as evoked response audiometry and otoacoustic emissions.

The study does not highlight about the cause of hearing impairment. Further studies are required to know the mechanism of hearing loss in school children exposed to noise pollution.

CONCLUSION: The study revealed that children from more noisy area had significantly raised air and bone conduction thresholds at all frequencies and also increased prevalence of hearing impairment in the same children.

There is need to creating general awareness towards the hazardous effects of noise pollution. Particularly, in our country people generally lack consciousness regarding the ill effects of noise pollution and how the society including they themselves stand to benefit from preventing generation and emission of noise pollution. The target area should be educational institutions and more particularly school.

\section{BIBILIOGRAPHY:}

1. Chaturvedi VN, Hearing Impairment \& Deafness - Magnitude of Problem and Strategy for Prevention. IJO \& HNS 1999; 51 (2): 2.

2. Deafness and Hearing Impairment. WHO factsheet N0 300. Geneva: World Health Organisation: 2006. www.who.int/mediacentre/factsheets/ fs300/en/index.html.

3. Mauk GK, White KR, Mortensen LB, Behrens TR. The effectiveness of screening programs based on high - risk characteristics in early identification of hearing loss. Ear Hear 1991; 12; 312 - 9.

4. Sharma H, Bhushan V, Dayal D, Mishra S. Preliminary study of hearing handicap in school goind children. Indian J. Laryngol Otol Head Neck Surg 1992; 1 (3); 119 - 24.

5. Ana GR, Shendel DG, Brown GE, Sridhar MKC - Assessment of noise and associated health impacts at selected secondary schools in Ibadan, Nigeria. J Environ Public Health. 2009;

6. Broste SK et.al. Hearing loss among high school farm students. AJPH May 1989, vol. 79, No.5.

7. Consuelo MD et.al. Sensorineural hearing loss in high school teenagers in Mexico city and its relationship with recreational noise. Saude publica vol.25 no.12 Rio de Janeiro Dec. 2009. 
8. Niskar AS et.al. Estimated prevalence of noise- induced hearing threshold shifts among children 6 to 19 years of age: The third national health and nutrition examination survey, 1988-1994, United States. Pediatrics Vol. 108 No. 1 July 2001, pp. 40-43.

9. Ludman H, Wright T, editors. Diseases of the ear. $6^{\text {th }}$ ed. Jaypee publications; 483-86.

10. Ramazan Mirzaei, Alireza Ansari-Mogaddam, Mahdi Mohammadi, Fatemeh Rakhshani, Maryam Salmanpor. Noise pollution in Zahedan and residents' knowledge about noise pollution.J health Scope 2012;1(1): 3-6

Graph 1; Age distribution of subjects studied
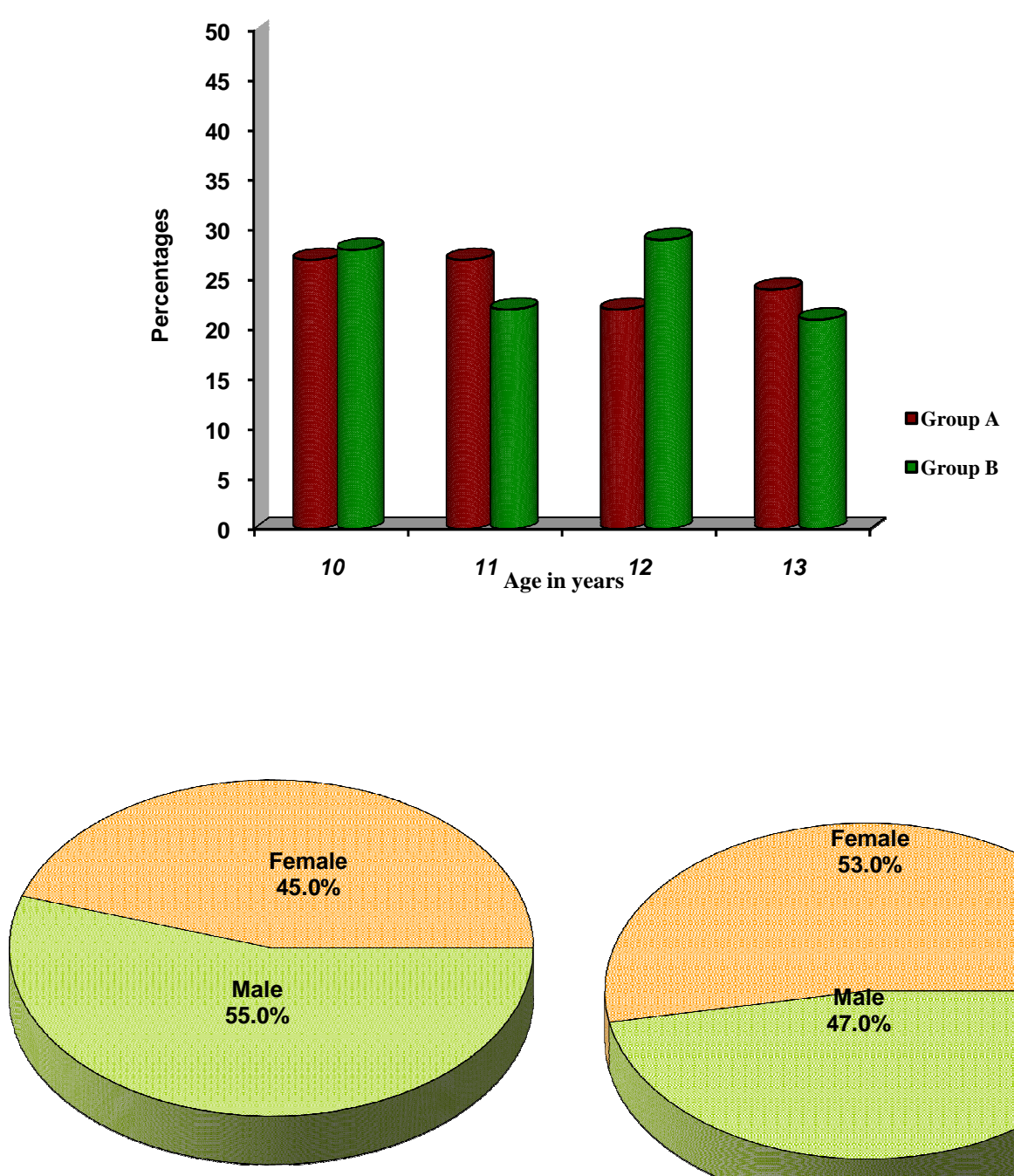

Group A

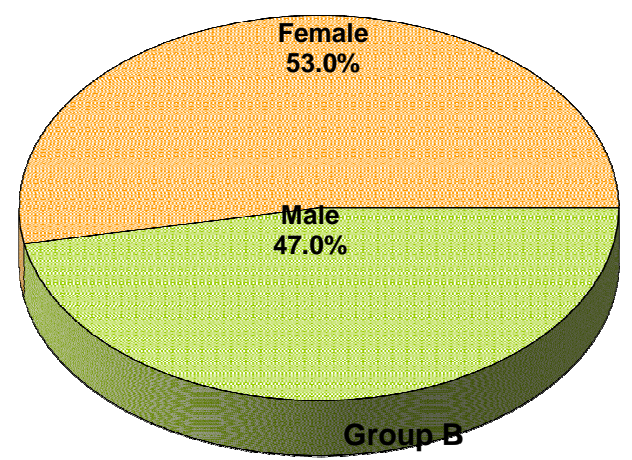

The gender distribution of subjects included in the study is depicted in table 3 and graph 2 . The study groups are age matched as the p value is 0.258 . 


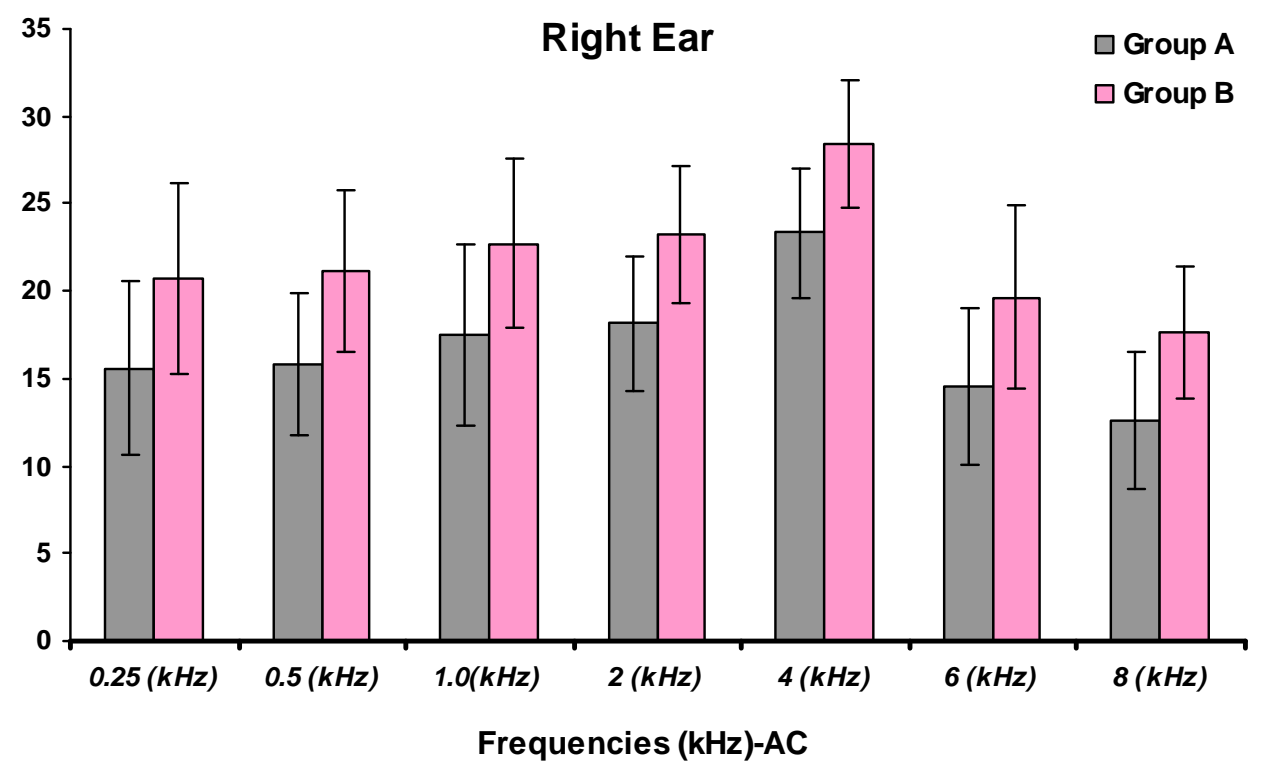

Graph 3a; Comparison of thresholds of air conduction in right ear between two groups.

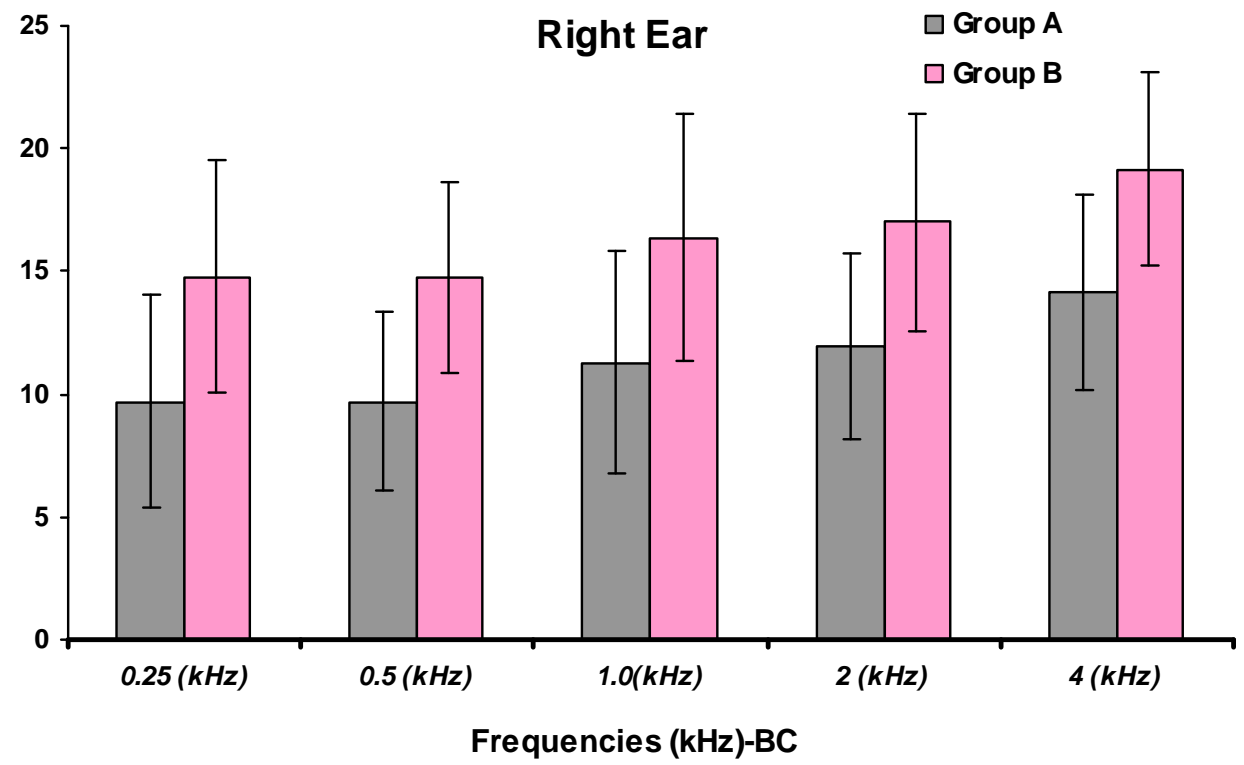

Graph 3b; Comparison of thresholds of bone conduction in right ear between two groups. 


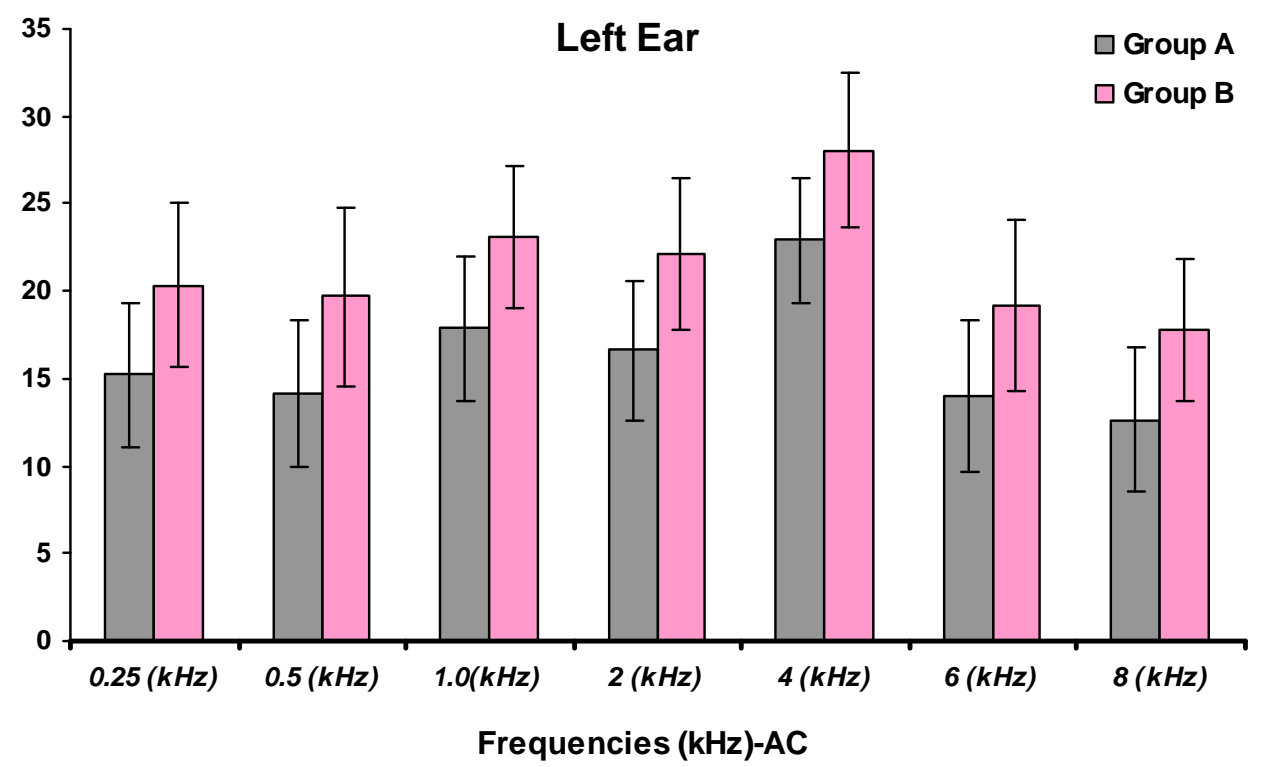

Graph 4a ; comparison of thresholds of air conduction in left ear between two groups.

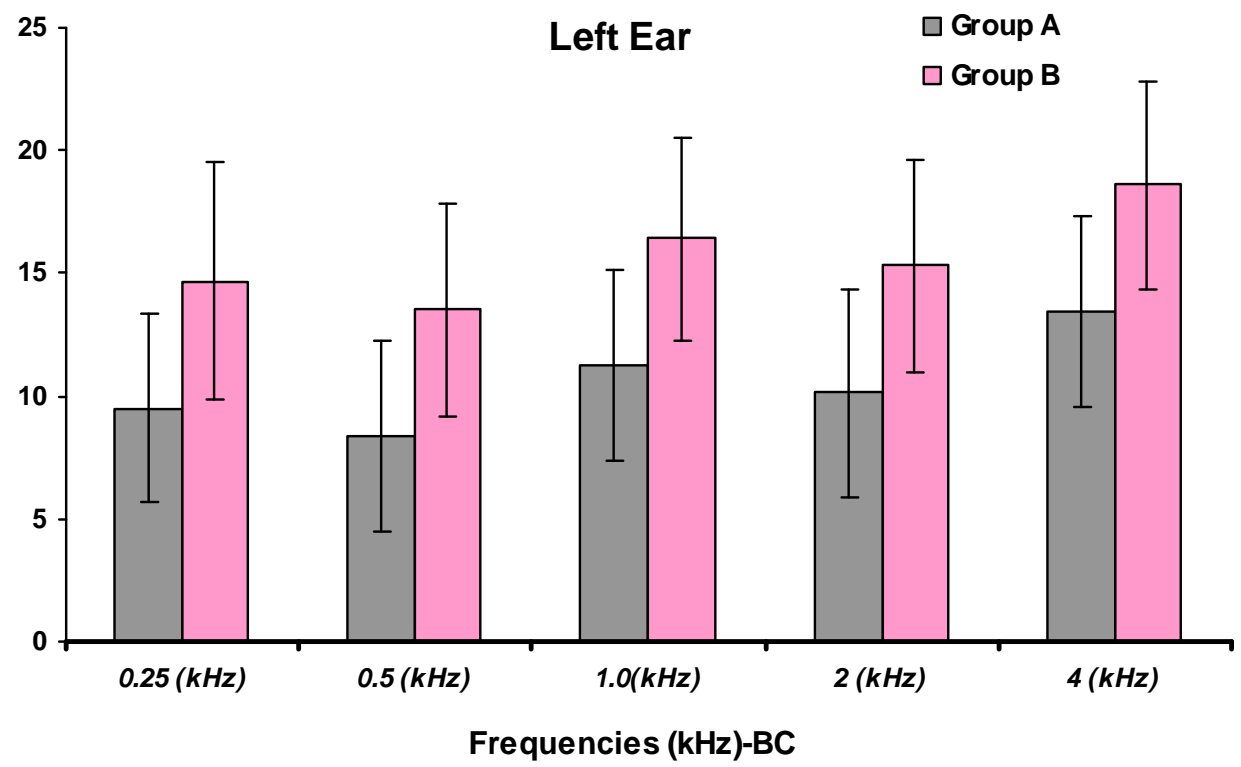

Graph 4b; comparison of thresholds of bone conduction in left ear between two groups. 


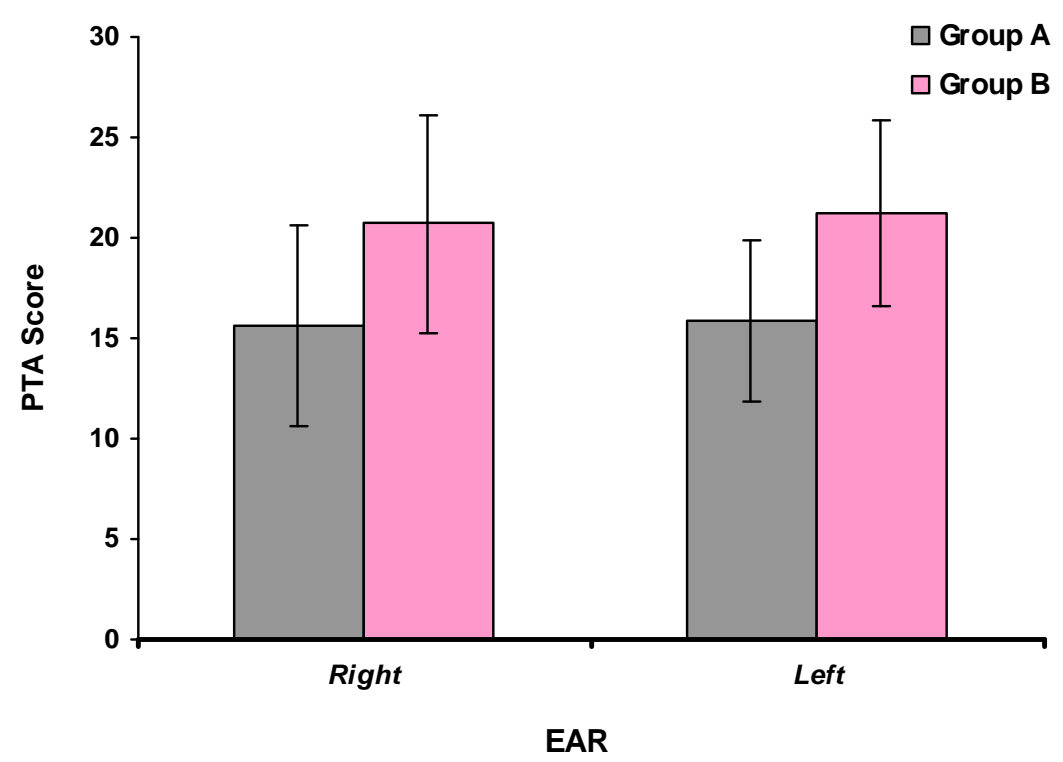

Graph 5; Comparison of PTA scores between two groups.

Above graph indicate that the pure tone average of left and right ears increased significantly in group B when compared with group A . $(\mathrm{p}<0.001)$

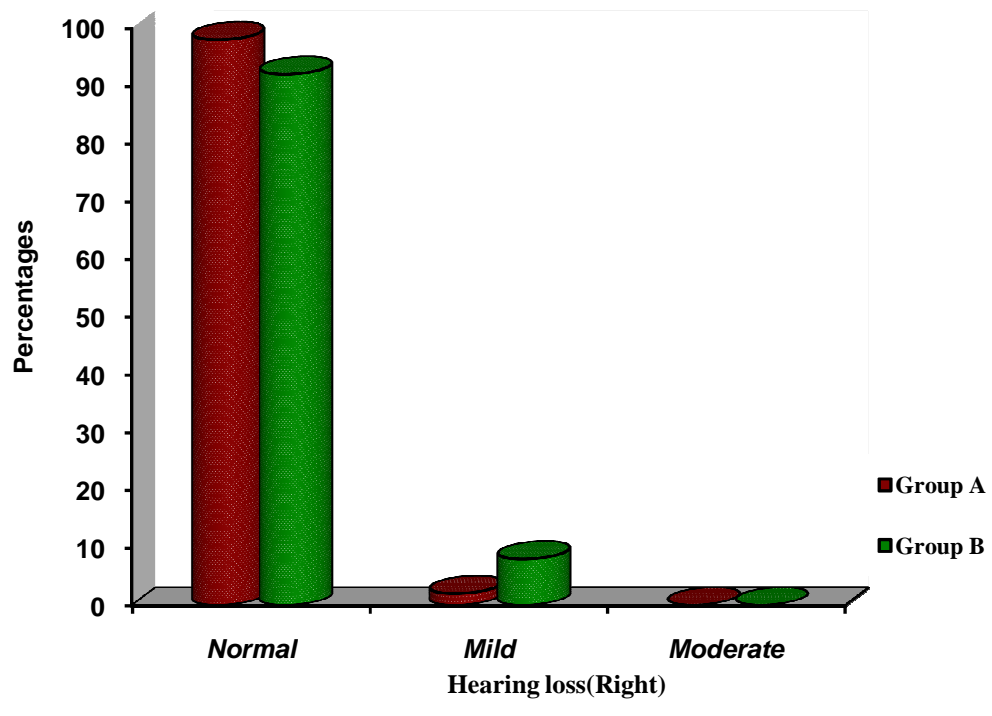

Graph 6; Comparison of hearing loss between two groups in Right ear.

The above table and graph show the degree of hearing impairment in right ear in two groups the incidence of hearing loss is positively associated in group $B(p=0.101$ 


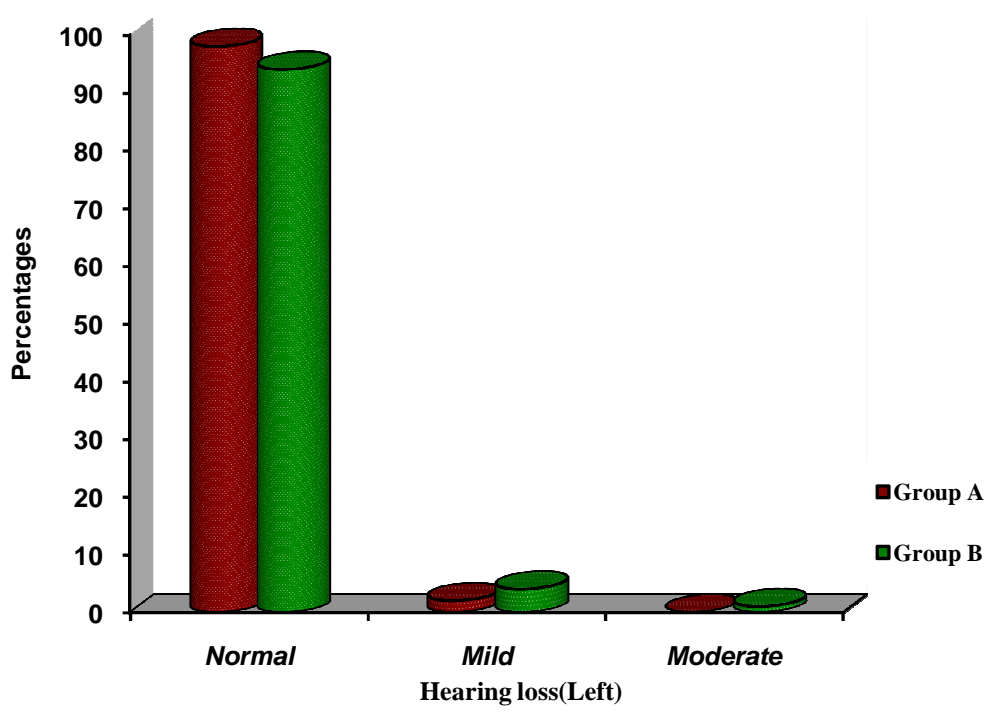

Graph 7; comparison of hearing loss between two groups in left ear.

The above table and graph show the degree of hearing impairment in left ear in two groups. The incidence of hearing loss is positively associated in group B. 